\title{
Language Education in the Age of Globalization and Innovation
}

\author{
$V$. Dobrova $^{1, *}, P$. Labzina $^{1}, N$. Ageenko $^{1}$, and $S$. Menshenina $^{1}$ \\ ${ }^{*}$ Corresponding author: victoria_dob@mail.ru. \\ ${ }^{1}$ Samara State Technical University, Samara, Russia
}

\begin{abstract}
Globalization and innovation have recently resulted in the extensive use of the latest technological products practically everywhere, and in education especially. Various technologies are now employed in different spheres of education. Virtual Reality (VR) is a global innovative technology with great potentials and enormous pedagogical possibilities that offers new methods and techniques for education. The main features of it are visibility, security, involvement, presence and focusing. It enables to combine the computer-generated virtual information and the real environment in real time. The presented VR language program is based on the concept of $3 \mathrm{D}$ modeling and semantic frame method.
\end{abstract}

Keywords: language education, globalization, innovation, virtual reality.

\section{Introduction}

Globalization has become a widely discussed idea in national and international context in recent years. Yet the term "globalization" is relatively new, and its meaning and impact remain essentially contested within the research community.

R. Robertson [1], whose name is closely associated with globalization theory, considers globalization as an accelerated compression of the modern world and also as the intensification of world consciousness as a singular entity. Some researches believe that globalization is the process of the world changing so that individuals can communicate to each other immediately through the use of various technologies and especially the internet. Others consider globalization to be a social change at which physical presence of place on the social, educational and cultural aspects are diminishing, and the general public know that it is diminishing [2]. Therefore, it can be said that globalization is the weakening of the physical boundaries associated with countries and nations that affects various spheres of human life such as economy, politics, education, social interaction, culture and many other aspects, and promotes technological progress.

\section{Globalization and Education}

\subsection{Impact of globalization on education}

It is becoming obvious that processes of globalization have impact on education around the world in many important ways. As education plays a great role in shaping a society, so globalization has to be associated with education thus having a deep impact on it.

The brief categorization of globalization show that some authors mention the following effects of globalization in education: commodification, internationalization, citizenship and accessibility of knowledge [2]. World globalization aims at increasing attention to the internationalization of the academic studies subjects thus creating the opportunities for new international partnerships in teaching and research with companies and institutions across the world [3]. Another impact of globalization on education is the general accessibility of knowledge. With the use of the internet knowledge is readily accessible, that leads to the faster acquisition of knowledge by individuals as they have a wide range of information and knowledge available for them there. This makes possible that teachers and learners can create a global understanding of education on the basis of their communication with different people from around the whole world.

The effects of globalization lead to important changes in education by bringing rapid developments in communication and technology that foresees changes within education systems across the world in terms of values, ideas and knowledge, that also change the roles of teachers and students, and what's more produce a shift from the industrial society towards the information-based one. With such changes the distance barriers are easily being broken down due to the key aspect of globalization. People of all ages got an opportunity to learn in every suitable way, to attend live and virtual classes, and they don't need to be present in a class or an educational institution physically in order to learn. It allows for individuals to explore new horizons of thinking and learning that could not be done in the traditional educational environment with pen and paper and a teacher that dominates the classroom setting. Now knowledge can be gained through experimentation and inquiry. 


\subsection{Use of innovative technologies}

Globalization and innovation have recently resulted in the extensive use of the latest technological products practically everywhere, and in education especially. Various technologies are now employed in different spheres of education. With the beginning of today's Digital Era the information and communication technology has been developed allowing real-time communication across space and time zones in one common environment reachable from everywhere around the globe - the virtual reality (VR). Thus, virtual environment enables the access of broad public to civilization knowledge, allows to share and acquire expertize in various fields across borders without geographical limitations [4].

These advantages are continuously being integrated into the educational sector. The use of VR in education is considered to be one of the global natural evolutions of IT- and computer-based training. The conducted analysis proved that the virtual environment stimulates learning, comprehension and reproduction, as it provides a tight and unique combination of experiential and symbolic information. VR is changing the way people learn in global and interesting ways. Rather than looking out the window, students could potentially see exactly what their teacher is talking about.

Immersing students in what they're learning has the potential to truly engage and increase their overall comprehension, no matter what type of learning method they prefer. Thus, VR in education provides the following benefits:

- Prevailing of the active experience over the passive one;

- Gaining of unforgettable great experience with no distractions;

- Getting immediate engagement;

- Helping trainees to understand complex phenomenon and subjects;

- Time compression.

Today information technology is widely used everywhere from educational establishments to the work places all over the world [5]. In schools in Japan, China and the USA such VR technologies and VR environments are commonly used, and VR lessons take a great part of their curriculum. In Russia it hasn't become general practice yet. So far VR lessons and materials are not included in the compulsory educational program, the legal, physiological and psychological aspects of VR usage have not been studied, though several cases of VR classes implementation have already taken place. For the Russian reality it means that the supplemented reality in learning and teaching is applied only by adding interactive materials into the ordinary textbooks. For example, when a student points a camera, tablet or phone on a picture in a textbook, he can see a molecule structure or a Maxican pyramid in 3D, study it from different angles, move it or interact with it primitively on the device screen. Another example is about implementation of vidoe materials such as a video of a biological process or a chemical reaction.

Some researcher determine the problem of modern higher education as the lack of new and effective approaches to learning and teaching [6]. He criticizes the use of lecture rooms with rows of seats as the main physical learning space for studying and teaching in higher education. Thus, he suggests to use such learning spaces as blended, physical/virtual, mobile, formal/informal, professional and to consider adaptability, flexibility, and time. Such learning spaces will reflect up-to-date learning and teaching techniques and strategies thus emphasizing individual and peerbased learning both in physical and virtual learning environments. In the educational sector in Russia, the use of VR technologies is a rare practice and the preference is still given to the older and more traditional methodologies.

While education institutions of highly developed countries are adopting technology rather effectively, less developed societies are left behind, hardly implementing development programs for education. A lack of funding and infrastructure hardly makes possible the implementation of any communication or technological development. However, notwithstanding the differences in politics, economy, culture and education, advanced and underdeveloped economies have adopted the best educational ideals and are anxious to rise education and promote it as a symbol of modernity and development, as a result of globalization.

\section{Language Education in VR}

\subsection{VR in teaching}

The application of VR was originally designed for aviation to visualize flights for pilots training, healthcare to visualize surgical operations, way finding and architecture to visualize large-scale projects. Now it became obvious that it can be widely implemented to teaching due to its unlimited possibilities and universal character.

The most general features of VR educational environment are:

- the use of 3D vector geometry when modelling the environment,

- unlimited movement possibilities for the users,

- updated views of the users as they move through the environment,

- the objects respond to the user action within the virtual environment,

- 3D audio.

Many researchers $[7,8]$ emphasize such a possibility of VR as to operate and act in the environments that are hardly or not accessible to individuals due to distance, scale, time and security. 
The following possibilities of VR in education were singled out:

1) Visibility - as the use of $3 \mathrm{D}$ graphics makes it possible to detail various phenomena and processes $[9,10]$. VR is able to provide information as well as to demonstrate the phenomenon with various details.

2) Security - as VR can immerse the person in any circumstance without any threat to life.

3) Involvement - as VR makes it possible to influence the reality and interact with it. For example, one can change the course of an experiment, drive a spaceship, etc.

4) Focusing - as the virtual world is designed specially to allow the viewer to concentrate entirely on the material and not distract on external stimuli like in the real world.

5) Presence - as an individual has a first person view and a sense of presence in VR world.

\subsection{Innovative language training system}

The team of Samara State Technical University, Russia designed and implemented the innovative educational VR course of English that creates a real situation of interaction allowing the student to make contacts, to give and receive certain information, to practice scientific research and educational techniques, to be engaged in project activities [11]. By introducing this course the students got the opportunity to understand the processes and situations that can hardly be explained in the traditional settings, to become a part of the real world through VR simulation.

It's obvious that the total immersion of a student into the real language environment can give results that both teachers and students are looking for. The educational process in classrooms can't replace this real experience of learning, no matter how well-organized, creative and communicative it is. Educators will agree that effective language learning depends on the motivation and the right language environment. As the majority of people who study a foreign language cannot afford to do it abroad, educators and teachers are searching for the alternative methods and inventing training models that are close to the natural and real language environment.

Today VR combines the two main factors for effective learning - immersion and motivation. VR allows students to immerse into another nation's culture for little or no cost. Students will definitely be interested in learning with VR technologies as it offers unique learning experiences by providing of real-time three-dimensional visualization and by introducing of various interactivity types within virtual learning environment.

With the help of VR a foreign language teacher can easily immerse a student into a real situational interaction, for example, a job interview, the situation in a shop, street, etc. VR space can be developed and adjusted according to the study objectives, time limits, number of participants, language level, animated or real characters, preferable devices, etc. It is flexible and convenient in use - that is a key factor for the students to use this technology in learning. Besides it helps to solve many problems of traditional learning. The new designed generational course of English «VR Customs» is based on three-dimensional VR technology. The minimum set necessary for using the program is a laptop or PC and VR glasses.

The language material was selected and organized on the basis of the frame technology. This is a convenient tool for carrying out the task of structuring a situation. If it is necessary to structure a dynamic situation, and this is exactly our case, it is customary to use a frame script. This is a dynamic structure in which elements are scanned, "run" by the mind's eye in a certain sequence $[12,13]$. Scripts are characterized by the fact that they describe not objects and not static states of affairs, but events unfolding in time, which add up to the situation by forming a sequence. Thus, on the basis of script and frame description methodology, the structure of various classes of situations were characterized and described [14].

The virtual environment where the student receives information and makes a virtual inspection is the international airport. The main goal is learning and training professional English for customs officers. We have three locations - the main hall of the airport, red channel and green channel. The student has to interact with passengers, workers of the airport and do their tasks to find a smuggler. They give the student tasks like bringing documents they have lost somewhere, or choosing necessary bags from the porter's list of luggage. After doing exercises passengers give some hints and features of the smuggler the student is looking for. So at the end he does the final test and helps the customs officer find the smuggler. The next level is the red and green channel, where customs officers work. Students can learn the names of prohibited items and goods customs officers work with every day. Students listen to the dialogues that contain the most used expressions and terms. The customs officer interacts with the passenger, asks about his declaration, baggage, presence of prohibited items, valued things. Students can communicate with customs officers and get the necessary information about the Customs, job description and main responsibilities through the dialogue. Then the student should do lexical or grammar exercises to test the learned material.

So, the integrated learning system "Virtual Customs" is the universal innovative method of studing a foreign language as it uses the latest VR technologies. It also allows to train foreign language teachers from higher educational institutions to conduct lessons with the help of VR technologies taking as example the training system "Virtual Customs".

\section{Conclusions}

The information and communication technology has been evolutionary changing the known way of working and living through interconnecting people across time and space and enabling globalization. The revolutionary development of information and communication technology enabled the global information exchange to increase in volume and 
speed rapidly and continuously during last decades [15]. It created a new environment globally accessible for individuals for mutual interaction in one common place that is reachable from everywhere - the virtual world.

It should be mentioned that global education using VR allows you to conduct the training visually, to present all the aspects of the real processes and objects. As a whole it is highly effective, inhances the quality and the speed of the educational process, reducing its cost. With the help of VR technology a person can fully use the information from the outside world as $80 \%$ of it an individual perceives visually, $20 \%$ an individual remembers if only sees, $40 \%$ if sees and hears, and $70 \%$ is he sees, hears and does.

In general, VR can be considered an ideal learning environment. Its possibilities for teaching and studing have very high potential for application in a global sense. The full immersion in the professional environment allows students to build an individual way of studying the discipline alone or use it as an additional source.

\section{References}

1. R. Robertson, Globalization: Social theory and global culture (SAGE, Thousand Oaks, 1992).

2. Essays, UK, The definition of globalization education essay (2018). URL: https://www.ukessays.com/essays/education/the-definition-of-globalization-education-essay.php?vref=1. Accessed: 01.10 .2018 .

3. C.A, Twiggs, D.G. Oblinger, The virtual university. A report from a joint Educom/ IBM round table. Washington, Washington D.C. (1996). URL: https://www.educause.edu/ir/library/html/nli0003.html. Accessed: 22.11.2018.

4. M. Dávideková, J. Hvorecký, Collaboration tools for virtual teams in terms of the SECI model. Advances in Intelligent Systems and Computing, 544, 97-111 (2016).

5. P. Standen, D. Brown, Mobile learning and games in special education. The SAGE handbook of special education, 2 , 719-730 (2014).

6. M. Keppell, K. Souter, M. Riddle, Physical and virtual learning spaces in higher education: Concepts for the modern learning environment (IGI Publishing, Hershey, PA, United States, 2011).

7. M. Bricken, Virtual reality learning environments: Potentials and challenges, computer graphics. ACM SIGGRAPH Computer Graphics, 25(3), 178-184 (1991).

8. J. Cromby, P. Standen, D. Brown, Using virtual environments in special education. VR in the Schools, 1(3), 1-4 (1995).

9. S.-Y. Yoon, J. Laffey, H. Oh, Understanding usability and user experience of web-based 3D graphics technology. International Journal of Human-Computer Interaction, 24(3), 288-306 (2008). DOI: doi:10.1080/10447310801920516.

10. K.M. Stanney, M. Mollaghasemi, L. Reeves, R. Breaux, D.A. Graeber, Usability engineering of virtual environments (VEs): Identifying multiple criteria that drive effective VE system design. International Journal of Human-Computer Studies, 58(4), 447-481 (2003).

11. V.V. Dobrova, P.G. Labzina, Virtual reality in teaching foreign languages. Bulletin of Samara State Technical University, Ser. Psychological and Pedagogical Sciences, 4(32), 13-20 (2016).

12. R.C. Schank, R.P. Abelson, Scripts, plans, goals and understanding: An inquiry into human knowledge structures (Hillsdale, Psychology Press, 1977).

13. G. Mushayabasa, Translation techniques in the Pershtta to Ezekiel: A frame semantics approach. Studia Semitica Neerlandica, 63 (Brill, Leiden, 2015).

14. O. Kistanova, V. Dobrova, V. Savitskiy, E.Gashimov, L. Nurtdinova, Modeling as a method of describing the lexical meaning structure. In E.Yu. Malushko, N.L Schamne, N.V. Martyushev (Eds.), Proceedings of the $7^{\text {th }}$ International Scientific and Practical Conference "Current Issues of Linguistics and Didactics: The Interdisciplinary Approach in Humanities". Advances in Social Science, Education and Humanities Research, 97, 125-130 (2017).

15. M. Dávideková, M. Greguš, The impact of globalization on team composition: Virtual and local team. In T.Kliestik (Ed.), Proceedings of the 16th International Scientific Conference Globalization and Its Socio-Economic Consequences (pp. 354-361). Rajecke Teplice: UNIV ZILINA (2016). 